\title{
Comparison of ventilatory threshold between subjects with and without proteinuria in Japanese
}

\author{
Nobuyuki Miyatake $^{1 *}$, Kenichi Shikata ${ }^{2,3}$, Hirofumi Makino ${ }^{3}$, Takeyuki Numata $^{4}$ \\ ${ }^{1}$ Department of Hygiene, Faculty of Medicine, Kagawa University, Kagawa, Japan; *Corresponding Author: \\ miyarin@med.kagawa-i.ac.jp \\ ${ }^{2}$ Center for Innovative Medicine, Okayama University Hospital, Okayama, Japan; \\ ${ }^{3}$ Department of Medicine and Clinical Science, Okayama University Graduate School of Medicine, Dentistry and Pharmaceutical \\ Sciences, Okayama, Japan; \\ ${ }^{4}$ Okayama Southern Institute of Health, Okayama Health Foundation, Okayama, Japan.
}

Received 20 April 2011; revised 30 May 2011; accepted 1 June 2011.

\begin{abstract}
We compared the levels of ventilatory threshold (VT) between subjects with and without proteinuria. We used data of 402 men and 413 women who were not taking any medications, aged 20 - 77 years, in this cross-sectional investigation study. Aerobic parameters at VT i.e. oxygen uptake, work rate and heart rate, and exercise habits were evaluated, which are considered to be cardio respiratory fitness. Proteinuria was measured by using urine strip devices. Forty three men $(10.7 \%)$ and 29 women (7.0\%) were diagnosed as having the proteinuria $( \pm \leqq)$. There were no significant relationships between proteinuria and exercise habits in both sexes after adjusting for age. Oxygen uptake at VT in subjects with proteinuria was significantly lower than that in subjects without proteinuria after adjusting for age in men. However, such link was not noted in women after adjusting for age $(p=0.9964)$. Finally, associations were attenuated after adjusting for age and exercise habits in both sexes. Among Japanese not taking medications, proteinuria might be a modifiable factor of VT, especially in Japanese men.
\end{abstract}

Keywords: Proteinruia; Ventilatory Threshold (VT); Exercise Habits

\section{INTRODUCTION}

Chronic kidney disease (CKD) has become an important public health challenge in Japan and it is a major risk factor for the end stage renal disease, cardiovascular disease and premature death [1,2]. For example, about $20 \%$ of adults have CKD, which is defined as kidney damage or a glomerular filtration rate $(\mathrm{GFR})<60 \mathrm{ml} / \mathrm{min}$
$/ 1.73 \mathrm{~m}^{2}$ for at least three months regardless of cause [3]. We have also previously reported in a cross-sectional study that the estimated glomerular filtration rate (eGFR) [4] in men with abdominal obesity and in women with hypertension was significantly lower than that in subjects without these components of metabolic syndrome [5]. In addition, we have also showed that proteinuria was closely linked to lower eGFR and it might be useful marker for CKD in Japanese [6].

The ventilatory threshold (VT), which is one of parameters of the cardio respiratory fitness, is defined as the upper limit of the aerobic exercise and is thought to serve as an accurate and reliable standard for exercise prescription [7]. Since the exercise intensity at VT is not harmful to cardiovascular function, it can be safely applied to patients with myocardial infarction as exercise prescription [8]. However, the link between cardio respiratory fitness using VT and proteinuria remains to be investigated.

In this study, we investigated cardio respiratory fitness evaluated by VT in Japanese and evaluated the clinical impact of proteinuria on VT in subjects not taking medications.

\section{METHODS}

\subsection{Subjects}

We used all data on 815 Japanese (402 men and 413 women) aged 20 - 77 years in a cross-sectional study. All subjects met the following criteria: 1 ) they had wanted to change their lifestyle i.e. diet and exercise habits, and had received an annual health checkup at Okayama Southern Institute of Health; 2) they had received VT, urine examination and anthropometric measurements as part of their annual health checkups; 3) they had received no medications for diabetes, hypertension, and/or 
dyslipidemia; and 4) they provided informed consent (Table 1).

The study was approved by the Ethics Committee of Okayama Health Foundation.

\subsection{Anthropometric Measurements}

The anthropometric parameters were evaluated by using the following respective parameters such as height, body weight, body mass index (BMI), abdominal circumference, and hip circumference. BMI was calculated by weight/[height $]^{2}\left(\mathrm{~kg} / \mathrm{m}^{2}\right)$. The abdominal circumference was measured at the umbilical level and the hip was measured at the widest circumference over the trochanter in standing subjects after normal expiration [9].

\subsection{Exercise Testing}

A graded ergometer exercise protocol [10] was performed. Two hours after breakfast, a resting ECG was recorded and blood pressure was measured. Then, all participants were given graded exercise after $3 \mathrm{~min}$ of pedaling on an unloaded bicycle ergometer (Excalibur V2.0, Lode BV, Groningen, Netherlands). The profile of incremental workloads was automatically defined by the methods of Jones [10], in which the workloads reach the predicted $\mathrm{VO}_{2}$ max in $10 \mathrm{~min}$. A pedaling cycle of 60 rpm was maintained. Loading was terminated when the appearance of symptoms forced the subject to stop. During the test, ECG was monitored continuously together with the recording of heart rate (HR). Expired gas was collected and rates of oxygen consumption $\left(\mathrm{VO}_{2}\right)$ and carbon dioxide production $\left(\mathrm{VCO}_{2}\right)$ were measured breath-by-breath using a cardiopulmonary gas exchange system (Oxycon Alpha, Mijnhrdt b.v., Netherlands). VT was determined by the standard of Wasserman et al [7], Davis et al [11], and the V-slope method of Beaver [12] from $\mathrm{VO}_{2}, \mathrm{VCO}_{2}$ and minute ventilation (VE). At VT, $\mathrm{VO}_{2}(\mathrm{ml} / \mathrm{kg} / \mathrm{min})$, work rate $(\mathrm{W})$, and heart rate (beats/ min) were measured and recorded.

\subsection{Urine Examination}

Urine samples were collected from the second-morning urine (before 10 a.m.) and examined within 1 hour. The urine examination was performed using urine strip tests (BAYER, Tokyo, Japan). The reagent strip was dipped directly into the urine sample. Just after dipping, the sample is graded as -: negative, \pm : trace positive, + : positive $(30 \mathrm{mg} / \mathrm{dl}), 2+$ : positive $(100 \mathrm{mg} / \mathrm{dl}), 3+:$ positive $(300 \mathrm{mg} / \mathrm{dl})$ or $4+$ : positive $(1000 \mathrm{mg} / \mathrm{dl})$ by comparison with a standard color chart found on the container's label [13].

\subsection{Exercise Habits}

The data on exercise habits was obtained at interviews by well-trained staff in a structured way. The subjects were asked if they currently exercise (over the level of 30 minutes per time, two times per week and prolong duration for 3 months). When the answer was "yes", they were classified as subjects with exercise habits. When the answer was "no", they were classified as subjects without exercise habits.

Table 1. Clinical profiles of enrolled subjects.

\begin{tabular}{|c|c|c|c|c|c|c|}
\hline & \multicolumn{3}{|c|}{ Men } & \multicolumn{3}{|c|}{ Women } \\
\hline & $\mathrm{Men} \pm \mathrm{SD}$ & Minimum & Maximum & $\operatorname{Men} \pm \mathrm{SD}$ & Minimum & Maximum \\
\hline Number of subjects & 402 & & & 413 & & \\
\hline Age & $42.3 \pm 11.5$ & 20 & 77 & $45.1 \pm 12.1$ & 20 & 71 \\
\hline Height $(\mathrm{cm})$ & $169.7 \pm 5.9$ & 152.2 & 187.2 & $156.1 \pm 5.5$ & 141.7 & 176.1 \\
\hline Weight (kg) & $78.8 \pm 13.1$ & 45.3 & 121.9 & $64.9 \pm 12.0$ & 39.9 & 116.9 \\
\hline Body mass index $\left(\mathrm{kg} / \mathrm{m}^{2}\right)$ & $27.3 \pm 4.1$ & 16.8 & 41.5 & $26.6 \pm 4.8$ & 15.4 & 48.7 \\
\hline Abdominal circumference $(\mathrm{cm})$ & $90.9 \pm 10.8$ & 62.5 & 130.0 & $81.5 \pm 11.3$ & 56.0 & 123.6 \\
\hline Hip circumference $(\mathrm{cm})$ & $98.5 \pm 6.8$ & 79.8 & 120.0 & $96.6 \pm 8.5$ & 72.5 & 132.0 \\
\hline Heart rate at rest (beat/min) & $73.6 \pm 12.4$ & 43.0 & 117.0 & $73.2 \pm 11.9$ & 6.0 & 135.0 \\
\hline Systolic blood pressure (mm Hg) & $137.3 \pm 16.7$ & 102.0 & 191.0 & $135.0 \pm 20.9$ & 82.0 & 188.0 \\
\hline Diastolic blood pressure (mm Hg) & $86.1 \pm 12.2$ & 54.0 & 131.0 & $83.0 \pm 12.8$ & 50.0 & 122.0 \\
\hline Oxygen uptake at ventilatory threshold (ml/kg/min) & $14.9 \pm 3.9$ & 8.7 & 33.9 & $12.6 \pm 2.5$ & 7.8 & 27.3 \\
\hline Work rate at ventilatory threshold (watt) & $82.8 \pm 24.5$ & 35.0 & 190.0 & $51.2 \pm 14.8$ & 15.0 & 125.0 \\
\hline Heart rate at ventilatory threshold (beat/min) & $105.9 \pm 11.9$ & 70.0 & 149.0 & $106.8 \pm 11.7$ & 71.0 & 147.0 \\
\hline
\end{tabular}




\subsection{Statistical Analysis}

All data are expressed as mean \pm standard deviation (SD) values. A statistical analysis was performed using an unpaired $t$ test, $\chi^{2}$ test, logistic regression analysis and covariance analysis, where $p<0.05$ was considered to be statistically significant. We used the unpaired $t$ test to compare parameters between subjects with and without proteinuria; the $\chi^{2}$ test was used to evaluate the relationship between prevalence of proteinuria and exercise habits. Logistic regression analysis and covariance analysis were also used to adjust for parameters. ANOVA and Scheffe's F test were also used to compare among subjects with and without proteinuria and exercise habits.

\section{RESULTS}

Clinical profiles are summarized in Table 1. Oxygen uptake at VT was $14.9 \pm 3.9 \mathrm{ml} / \mathrm{kg} / \mathrm{min}$ in men and 12.6 $\pm 2.5 \mathrm{ml} / \mathrm{kg} / \mathrm{min}$ in women. Prevalence of proteinuria in enrolled subjects is also summarized in Table 2. A total of 43 men (10.7\%) and 29 women $(7.0 \%)$ was diagnosed as having the proteinuria ( $\pm \leqq$ ).

We further evaluated the relationship between proteinuria and exercise habits (Table 3). Significant relationships between proteinuria and exercise habits were not noted in both sexes after adjusting for age.

We compared the parameters at VT between subjects with and without proteinuria (Table 4). In men, oxygen uptake at VT in subjects with proteinuria was significantly lower than that in subjects without proteinuria even after adjusting for age by using covariance analysis $(p=0.0114)$. It is well known that exercise habits are closely associated with ventilatory threshold [14], and significant difference of oxygen uptake at VT was attenuated after adjusting for age and exercise habits ( $p=$ 0.4628). The significant differences of work rate and heart rate at VT were not noted in men. In women, parameters at VT in subjects with proteinuria were not significant different compared to those in subjects without proteinuria.

We finally compared parameters at VT between subjects with and without proteinuria and exercise habits [A: proteinuria (-) exercise habits $(+)$, B: proteinuria $(-)$ exercise habits $(-), \mathrm{C}$ : proteinuria $(+)$ exercise habits $(+), \mathrm{D}$ : proteinuria $(+)$ exercise habits $(-)$ ] (Table 5). In men, oxygen uptake at VT in Group B and D was significantly lower than that in Group A. Heart rate at VT in Group D was significantly higher than that in Group A. In women, oxygen uptake at VT in Group B was significantly lower than that in Group A. Heart rate at VT in Group D was significantly higher than that in Group A.

\section{DISCUSSION}

In this study, we firstly evaluated the link between proteinuria and cardiorespilatory fitness using VT in Japanese without any medications. Proteinuria might be a modifiable factor of VT, especially in Japanese men.

It is well known that proteinuria and/or reduced renal function were closely associated with cardio vascular disease (CVD) $[15,16]$. Irie et al reported that they evaluated 30,764 men and 60,668 women aged $40-79$ years for 10 years, and proteinuria and hypercreatinemia or reduced GFR and their combination were significant predictors of CVD and all-cause mortality [15]. Anavekar et al also showed that even mild renal disease

Table 2. Prevalence of proteinuria in enrolled subject.

\begin{tabular}{|c|c|c|c|c|c|c|c|c|c|c|c|}
\hline & \multicolumn{2}{|c|}{-} & \multicolumn{2}{|c|}{ \pm} & \multicolumn{2}{|c|}{$1+$} & \multicolumn{2}{|c|}{$2+$} & \multicolumn{2}{|c|}{$3+$} & \multirow{2}{*}{ Total } \\
\hline & & $\%$ & & $\%$ & & $\%$ & & $\%$ & & $\%$ & \\
\hline Men & 359 & 89.3 & 21 & 5.2 & 14 & 3.5 & 5 & 1.2 & 3 & 0.7 & 402 \\
\hline Women & 384 & 93.0 & 17 & 4.1 & 9 & 2.2 & 3 & 0.7 & 0 & 0.0 & 413 \\
\hline
\end{tabular}

Table 3. Relationship between proteinuria and exercise habits.

\begin{tabular}{|c|c|c|c|c|}
\hline & Proteinuria $(-)$ & Proteinuria $( \pm \leqq)$ & $p$ & $p$ (After adjusting for age) \\
\hline Men & & & \multirow{3}{*}{0.0688} & \multirow{3}{*}{0.0921} \\
\hline Exercise habits $(+)$ & 152 & 12 & & \\
\hline Exercise habits (-) & 207 & 31 & & \\
\hline \multicolumn{5}{|l|}{ Women } \\
\hline Exercise habits $(+)$ & 105 & 4 & \multirow{2}{*}{0.1104} & \multirow{2}{*}{0.1667} \\
\hline Exercise habits $(-)$ & 279 & 25 & & \\
\hline
\end{tabular}


Table 4. Comparison of parameters at ventilatory threshold between subjects with and without proteinuria.

\begin{tabular}{|c|c|c|c|c|c|}
\hline & $\begin{array}{c}\text { Proteinuria } \\
(-)\end{array}$ & Proteinuria & \multirow{2}{*}{$p$} & \multirow{2}{*}{$\begin{array}{c}P \\
\text { (After adjusting } \\
\text { for age) }\end{array}$} & \multirow{2}{*}{$\begin{array}{c}p \\
\text { (After adjusting } \\
\text { for age age and } \\
\text { exercise habits) }\end{array}$} \\
\hline & Men \pm SD & Men \pm SD & & & \\
\hline \multicolumn{6}{|l|}{ Men } \\
\hline Number of subjects & 359 & 43 & & & \\
\hline Age & $42.7 \pm 11.5$ & $39.2 \pm 11.5$ & 0.0564 & & \\
\hline Oxygen uptake at ventilatory threshold $(\mathrm{ml} / \mathrm{kg} / \mathrm{min})$ & $15.1 \pm 4.0$ & $13.7 \pm 2.8$ & 0.0275 & 0.0114 & 0.4628 \\
\hline Work rate at ventilatory threshold (watt) & $83.3 \pm 25.3$ & $78.7 \pm 15.9$ & 0.2440 & 0.3603 & 0.2947 \\
\hline Heart rate at ventilatory threshold (beat/min) & $105.5 \pm 12.0$ & $109.1 \pm 11.2$ & 0.0591 & 0.4155 & 0.1050 \\
\hline \multicolumn{6}{|l|}{ Women } \\
\hline Number of subjects & 384 & 29 & & & \\
\hline Age & $45.2 \pm 12.2$ & $42.6 \pm 11.0$ & 0.2571 & & \\
\hline Oxygen uptake at ventilatory threshold $(\mathrm{ml} / \mathrm{kg} / \mathrm{min})$ & $12.6 \pm 2.5$ & $12.3 \pm 1.7$ & 0.5751 & 0.9964 & 0.2939 \\
\hline Work rate at ventilatory threshold (watt) & $51.2 \pm 15.1$ & $51.4 \pm 10.0$ & 0.9477 & 0.3446 & 0.2382 \\
\hline Heart rate at ventilatory threshold (beat/min) & $106.4 \pm 11.6$ & $112.2 \pm 12.5$ & 0.0102 & 0.4685 & 0.2028 \\
\hline
\end{tabular}

Table 5. Comparison of parameters of ventilatory threshold between subjects with and without proteinuria and exercise habits.

\begin{tabular}{|c|c|c|c|c|c|c|}
\hline & Proteinuria (-) & Proteinuria $(-)$ & & Proteinuria $(+)$ & Proteinuria $(+)$ & \\
\hline & Exercise habits $(+)$ & Exercise habits (-) & & Exercise habits $(+)$ & Exercise habits $(-)$ & \\
\hline \multicolumn{7}{|l|}{ Men } \\
\hline Number of subjects & 152 & 207 & & 12 & 31 & \\
\hline $\begin{array}{l}\text { Oxygen uptake at ventilatory threshold } \\
(\mathrm{ml} / \mathrm{kg} / \mathrm{min})\end{array}$ & $16.7 \pm 5.0$ & $13.9 \pm 2.6$ & $\mathrm{a}$ & $14.8 \pm 4.1$ & $13.2 \pm 2.0$ & a \\
\hline Work rate at ventilatory threshold (watt) & $90.9 \pm 31.0$ & $77.7 \pm 18.4$ & a & $74.5 \pm 16.3$ & $80.3 \pm 15.6$ & \\
\hline $\begin{array}{l}\text { Heart rate at ventilatory threshold } \\
\text { (beat/min) }\end{array}$ & $104.5 \pm 13.1$ & $106.1 \pm 11.1$ & & $103.1 \pm 12.4$ & $111.4 \pm 10.0$ & a \\
\hline \multicolumn{7}{|l|}{ Women } \\
\hline Number of subjects & 105 & 279 & & 4 & 25 & \\
\hline $\begin{array}{l}\text { Oxygen uptake at ventilatory threshold } \\
(\mathrm{ml} / \mathrm{kg} / \mathrm{min})\end{array}$ & $13.4 \pm 3.4$ & $12.3 \pm 2.1$ & a & $10.6 \pm 1.6$ & $12.6 \pm 1.6$ & \\
\hline Work rate at ventilatory threshold (watt) & $54.3 \pm 18.9$ & $50.0 \pm 13.2$ & & $41.2 \pm 9.5$ & $53.0 \pm 9.2$ & \\
\hline $\begin{array}{l}\text { Heart rate at ventilatory threshold } \\
\text { (beat } / \mathrm{min} \text { ) }\end{array}$ & $104.1 \pm 12.0$ & $107.3 \pm 11.3$ & & $101.8 \pm 11.6$ & $113.8 \pm 12.0$ & a \\
\hline
\end{tabular}

a: $p<0.05$ vs Proteinuria (-), Exercise habits (+)

was considered a major risk factor for CVD after myocardial infarction in 14527 patients with acute myocardial infarction [16]. However, according to the link between reduced renal function and cardiorespilatory fitness, there were few studies especially in Japan. Okuno et al reported that they evaluated 109 communitydwelling frail elderly, aged 65 years and over, and they found that functional reach and tandem stance were significantly affected by eGFR [17]. Takhreen reviewed that relationship between exercise intervention and qual- ity of life (QOL) in CKD patients. Exercising patients have shown improvements in physical fitness, psychological function, reaction times and lower extremity muscle strength, and these factors help improve QOL [18]. In this study, we solely evaluated the relationship between proteinuria and aerobic exercise level defined by VT in the Japanese without any medications. Exercise habits were not significantly linked to proteinuria in both sexes and the differences of parameters at VT between subjects with and without proteinuria were attenuated 
after adjusting for age and exercise habits in men. However, oxygen uptake at VT in women with proteinuria was not significantly lower than that in women without. In addition, we compared oxygen uptake at VT among subjects with and without proteinuria and exercise habits, and found that oxygen uptake at VT in Group D was the lowest among 4 groups in men. Oxygen uptake at VT in Group A was the highest among 4 groups in both sexes. Taken together, promoting exercise habits might be considered for improving aerobic exercise level, and proteinuria might be a modifiable factor of VT, especially in Japanese men.

Potential limitations still remain in this study. First, our study was a cross sectional and not a longitudinal study. Second, 402 men and 413 women in our study voluntarily underwent measurements: they were therefore more likely to be health-conscious compared with the average person. Third, we could not show clear mechanism between proteinuria and oxygen uptake at VT. We have previously reported that brachial-ankle pulse wave velocity (baPWV) in subjects with reduced eGFR was significantly higher than that in subjects without [19]. Arterial stiffness might affect the results. In addition, low prevalence of proteinuria also affected the results, especially in women. To show this, further prospective studies are needed in the Japanese.

\section{ACKNOWLEDGEMENTS}

This research was supported in part by Research Grants from the Ministry of Health, Labor, and Welfare, Japan. There are no conflicts of interest.

\section{REFERENCES}

[1] National Kidney Foundation. (2002) K/DOQI clinical practice guidelines for chronic kidney disease: evaluation, classification, and stratification. American Journal of Kidney Diseases, 39, S1-S266.

[2] Foley, R.N., Parfrey, P.S. and Sarnak, M.J. (1998) Clinical epidemiology of cardiovascular disease in choronic renal disease. American Journal of Kidney Diseases, 32, S112-S119. doi:10.1053/ajkd.1998.v32.pm9820470

[3] Imai, E., Horio, M., Iseki, K., Yamagata, K., Watanabe, T., Hara, S., Ura, N., Kiyohara, Y., Hirakata, H., Moriyama, T., Ando, Y., Nitta, K., Inaguma, D., Narita, I., Iso, H., Wakai, K., Yasuda, Y., Tsukamoto, Y., Ito, S., Makino, H., Hishida, A. and Matsuo, S. (2007) Prevalence of chronic kidney disease (CKD) in the Japanese general population predicted by the MDRD equation modified by a Japanese coefficient. Clinical and Experimental $\mathrm{Ne}$ phrology, 11, 156-163. doi:10.1007/s10157-007-0463-x

[4] Matsuo, S., Imai, E., Horio, M., Yasuda, Y., Tomita, K., Nitta, K., Yamagata, K., Tomino, Y., Yokoyama, H. and
Hishida, A. (2009) Revised equations for estimated GFR from serum creatinine in Japan. American Journal of Kidney Diseases, 53, 982-992. doi:10.1053/j.ajkd.2008.12.034

[5] Miyatake, N., Shikata, K., Makino, H. and Numata, T. (2010) Relationship between estimated glomerular filatration rate (eGFR) and metabolic syndrome in the Japanese population. Acta Medica Okayama, 64, 203-208.

[6] Miyatake, N., Shikata, K., Makino, H. and Numata, T. (2011) The relation between estimated glomerular filtration rate (eGFR) and proteinuria in okayama prefecture, Japan. Environmental Health and Preventive Medicine, 16, 191-195.

doi:10.1007/s12199-010-0183-9

[7] Wasserman, K., Whipp, B.J., Koyl, S.N. and Beaver, W.L. (1973) Anaerobic threshold and respiratory gas exchange during exercise. Journal of Applied Physiology, 35, 236-243.

[8] Weber, K.T. and Janicki, J.S. (1985) Cardiopulmonary exercise testing for evaluation of chronic cardiac failure. American Journal of Cardiology, 55, 22-31. doi:10.1016/0002-9149(85)90792-1

[9] (2005) Definition and the diagnostic standard for metabolic syndrome-Committee to Evaluate Diagnostic Standards for Metabolic Syndrome. Nippon Naika Gakkai Zasshi, 94, 794-809 (in Japanese).

[10] Jones, N.L., Makrides, L., Hitchcock, C., Chypchar, T. and McCartney, N. (1985) Normal standards for an incremental progressive cycle ergometer test. American Review of Respiratory Disease, 131, 700-708.

[11] Davis, J.A., Frank, M.H., Whipp, B.J. and Wasserman, K. (1979) Anaerobic threshold alterations caused by endurance training in middle-aged men. Journal of Applied Physiology, 46, 1039-1046.

[12] Beaver, W.L., Wasserman, K. and Whipp, B.J. (1986) A new method for detecting anaerobic threshold by gas exchange. Journal of Applied Physiology, 60, 2020-2027.

[13] Wallace, J.F., Pugia, M.J., Lott, J.A., Luke, K.E., Shihabi, Z.K., Sheehan, M. and Bucksa, J.M. (2001) Multisite evaluation of a new dipstick for albumin, protein and creatinine. Journal of Clinical Laboratory Analysis, 15, 231-235. doi: $10.1002 /$ jcla. 1032

[14] Miyatake, N., Miyachi, M., Tabata, I., Sakano, N., Suzue, T., Hirao, T. and Numata, T. (2010) Evaluation of ventilatory threshold and its relation to exercise habits among Japanese. Environmental Health and Preventive Medicine, 15, 374-380. doi:10.1007/s12199-010-0147-0

[15] Irie, F., Iso, H., Sairenchi, T., Fukasawa, N., Yamagishi, K., Ikehara, S., Kanasahiki, M., Saito, Y., Ota, H. and Nose, T. (2006) The relationships of proteinuria, serum creatinine, glomerular filtration rate with cardiovascular disease mortality in Japanese general population. Kidney International, 69, 1264-1271. doi:10.1038/sj.ki.5000284

[16] Anavekar, N.S., McMurray, J.J., Velazquez, E.J., Solomon, S.D., Kober, L., Rouleau, J.L., White, H.D., Nordlander, R., Maggioni, A., Dickstein, K., Zelenkofske, S., Leimberger, J.D., Califf, R.M. and Pfeffer, M.A. (2004) Relation between renal dysfunction and cardiovascular outcomes after myocardial infarction. The New England 
Journal of Medicine, 351, 1285-1295. doi:10.1056/NEJMoa041365

[17] Okuno, J., Tomura, S., Yanagi, H., Kim, M.J., Okura, T. and Tanaka, K. (2009) Evaluation of the association between impaired renal function and physical function among community-dwelling Japanese frail elderly based on the estimated glomerular filtration rate (eGFR). Nippon Ronen Igakkai Zasshi, 46, 63-70.

doi: $10.3143 /$ geriatrics. 46.63
[18] Takhreem, M. (2008) The effectiveness of intradialytic exercise prescription on quality of life in patients with chronic kidney disease. The Medscape Journal of Medicine, 10, 226.

[19] Miyatake, N., Shikata, K., Makino, H. and Numata, T. (2010) Relation between the estimated glomerular filtration rate and pulse wave velocity in Japanese. Internal Medicine, 49, 1315-1320.

doi:10.2169/internalmedicine.49.3085 